\title{
PENGUKURAN NILAI KEKERUHAN AIR PDAM TIRTA KEUMUENING KOTA LANGSA
}

\author{
Desy Monica ${ }^{1}$, Rahmawati $^{1}$ \\ ${ }^{1,1}$ Jurusan Fisika Teknik, Universitas Samudra \\ *email:desymonica282@gmail.com
}

\begin{abstract}
.
Practical work has been carried out at PDAM Tirta Keumieneng, Langsa City. This practical work discusses "Measurement of Water Turbidity in PDAM Tirta Keumuening Langsa City" which aims to find out how to measure the turbidity value of PDAM Tirta Keumueneng Langsa water and find out the functions of the turbidimeter and TDS meter. Turbidimeter is a tool for testing the turbidity of water with optical properties due to light dispersion, as a comparison of reflected light from incoming light seen from the level of turbidity with the Nephelometric Turbidity Unit (NTU). And TDS (Total Disolved Solids) is a tool to measure the number of particles (solids) dissolved in water or a tool that measures the concentration of hydroponic nutrient solutions (concentration of nutrient solutions) with units of ppm (Part Per Million = one million parts). The water treatment process at PDAM Tirta Keumuening Kota Langsa goes through several stages, namely suction/tapping (intake), storage and deposition (presidimentation), WTP/IPA (covering ploculation, sedimentation, and filtration), distribution or temporary storage (reservoir), and supply to consumers. The purification process for dosing is an affixing process. From the observations, the highest value in reservoir water is $152 \mathrm{Mg} / \mathrm{L}$ and river water is $118 \mathrm{Mg} / \mathrm{L}$. And the highest value for reservoir unit water is WTP/IPA I (55.3), WTP/IPA II (68.7), WTP/IPA III (75.5), WTP/IPA IV (25.1).
\end{abstract}

Keywords: Turbidimeter, TDS (Total Disolved Solids), and Nephelometric TurbidityUnit (NTU)

\section{PENDAHULUAN}

Air merupakan salah satu sumber daya alam yang sangat dibutuhkan manusia dalam kehidupan sehari-hari terutama air bersih. Pada umumnya air bersih digunakan untuk di konsumsi dan untuk keperluan MCK (mandi, cuci, kakus). Berdasarkan Peraturan Menteri Kesehatan RI No 492/MENKES/PER/IV/2020 Air dapat dikatakan bersih apabila memenuhi persyaratan fisik seperti tidak keruh, tidak berwarna, tidak berbau tidak berasa dan tidak berbusa, dengan uji kelayakan yaitu temperatur, kekeruhan, zat padat terlarut (TDS) dan kondutivitas air [1]. Adanya suatu standar air yang dapat dikonsumsi masyarakat dengan memenuhi syarat-syarat yang ditentukan. Di indonesia terdapat dua standar nasional yang mengatur kualitas air minum yaitu Standar Nasional Indonesia (SNI) 013553 - 1996 dari Departemen Perindustrian dan Perdagangan, yang menyatakan bahwa batas maksimal total angka kuman adalah $100 \mathrm{koloni} / \mathrm{ml}$ serta peraturan Menteri Kesehatan nomor 907/MENKES/SK/VII/2002, yang menyatakan bahwa air minum harus memenuhi persyaratan diantaranya tingkat kontaminasi 0 koloni / $100 \mathrm{ml}$ untuk keberadaan bakteri coliform [2].

Parameter kualitas air bersih juga diatur oleh Peraturan Menteri Perindustrian RI No. 78 tahun 2016 dengan ketentuan tingkat kekeruhan air bersih sebesar 25 NTU dan Total Dissolved Solids (TDS) sebesar $1500 \mathrm{mg} / \mathrm{L}$ [3]. Sumber air yang mampu menyediakan air yang baik yaitu dari segi kualitas dan kuantitas. Peningkatan kualitas air sangat diperlukan, terutama apabila air tersebut berasal dari air permukaan dengan memperhatikan syarat-syarat kebersihan, keamanan, dan kesehatan. Pengolahan yang dimaksud bisa dimulai dari yang sangat sederhana sampai yang pada pengolahan yang kompleks [4].

Di negara Indonesia khususnya daerah Kota Langsa telah didirikan instansi yang bertugas untuk melakukan pengolahan air bersih yang kemudian hasil pengolahan akan di aliri ke rumah-rumah masyarakat yang sudah berlangganan. Instansi tersebut bernama PDAM Tirta Keumuening Kota Langsa yang berlokasi di Desa Pondok Keumuening kota langsa. PDAM Tirta Keumuening Kota Langsa air yang dikelola bersumber dari air sungai di desa keumuening dan air waduk di PDAM yang selanjutnya dialirkan ke konsumen. Dalam kegiatan ini penulis melakukan Pengukuran Nilai Kekeruhan Air PDAM Tirta Keumuening Kota Langsa, dengan mengamati proses pengolahan air dan kualitas air PDAM Tirta Keumuening Kota Langsa yang akan disuplaikan kepada masyarakat atau konsumen. Tujuan dari kegiatan ini yaitu 
Melakukan pengukuran nilai kekeruhan air PDAM Tirta Keumuening Kota langsa dan mengetahui fungsi turbidimeter dan TDS meter.

Perusahaan Daerah Air Minum Tirta Keumuening merupakan salah satu perusahaan yang mengurus kebutuhan air minum khususnya di kota Langsa. Pada tanggal 21 Juni 2001 Pemerintah Kota Langsa yang menetapkan Perusahaan Daerah Air Minum berdasarkan UU RI No. 03 Tahun 2001 yang merupakan pemekaran dari Induk (Tirta Peusada) Kabupaten Aceh Timur. Instalasi Pengolahan Air bersih Keumuening pada awalnya dibangun oleh Pemerintah Kolonial Belanda tahun 1928 berupa Waduk Alur Gampu dengan Kapasitas 20-40 Lpd, Sand Filter, Jaringan perpipaan ACP dan GIP serta Water Toren air bersih Kapasitas $250 \mathrm{M}^{3}$ dipusat Kota Langsa untuk melayani pelanggan Kota Langsa pada saat itu. Kemudian pada tahun 1980 dibangun Water Treatment Plant ( WTP ) konvensional kapasitas 60 liter per detik ( Lpd ) melalui sumber dana IGGI dengan mengambil air baku bersumber dari sungai Krueng Langsa, yang dialirkan secara gravitasi melalui Upper Gruond pada ketinggian 47,2 m ke wilayah Kota Langsa dan sekitarnya.

Pada Tahun 2008 dibangun WTP plat baja dengan Kapasitas 60 L/detik oleh badan Rekontruksi dan Rehabilitasi (BRR). Dan juga pada Tahun 2013 dibangun dengan kapasitas 2 X 20 L/detik yang bersumber dari APBN. Jumlah pelanggan yang aktif untuk saat ini sebanyak 12.116 SR dan pada tahun 2018 jumlah pelanggan seluruhnya 14.174 SR. Ruang ruang lingkup usaha PDAM Tirta Keumuening adalah mengolah sumber air baku yang meliputi air sungai dari sungai alur gampong dan air waduk menjadi air bersih.

\section{METODE PENELITIAN}

Adapun waktu pelaksanaan kegiatan ini dilakukan selama 1 bulan, dimulai pada tanggal 11 Januari s/d 05 Februari 2021. Dilaksanakan setiap hari senin sampai dengan hari jum'at, pada jam kerja yang dimulai dari pukul 08:00-17:15 WIB. Tempat pelaksanaan Kerja praktek (KP) di Perusahaan Daerah Air Minum (PDAM) Tirta Keumuening Kota Langsa, Desa Pondok keumuening, Kecamatan Langsa Baro, Kota Langsa.

2.1. Proses Pengolahan dan Siklus Air PDAM Tirta Keumuening Kota Langsa.

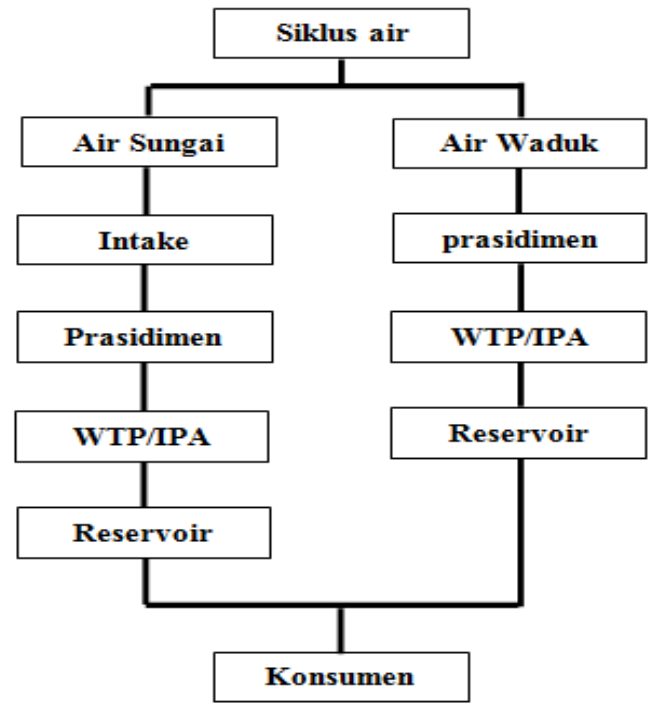

Gambar 1. Struktur Siklus Air PDAM Tirta Keumuening Kota Langsa

Adanya proses pembubuhan tawas yang digunakan untuk penjernihan air PDAM Tirta Keumuning Kota langsa. Pada saat proses pembubuhan, koagulant yang dibubuhkan merupakan bongkahan tawas yang dituang pada bak mixer berisi air. Kemudian bongkahan tawas tersebut diaduk selama waktu yang diperlukan. Terjadinya dua proses pengadukan kougulant pada saat pembubuhan yaitu pengadukan cepat dan pengadukan lambat. Pada pengadukan cepat bertujuan untuk mendispersikan koagulant secara merata ke dalam air baku untuk memacu pembentukan flok. Dan juga merupakan suatu proses untuk meratakan koagulant yang ditambahkan agar dapat bercampur dengan air baku pada wadah prasidimentasi secara baik. 
Pengambilan data mengunakan alat Turbidity meter dan alat ukur TDS. Pengukuran data mengunakan alat Turbidity meter dilakukan dengan menggunakan botol sampel (botol kaca kecil) untuk memasukkan sampel air. Botol sampel tersebut dimasukkan air dengan batas yang sudah ditentukan, kemudian masukkan botol pada alat turbidimeter terakhir tutup penutup alat dan menekan tombol read. Maka nilai kekeruhan air akan muncul pada layar digital. Untuk ukuran partikel yang terlarut pada sampel dapat mempengaruhi hasil pengukuran dari turbidimeter, dimana bentuk dan ukuran partikel akan mempengaruhi nilai intensitas dari transmisi dan hambur balik cahaya yang dibaca oleh sensor [5].

Penggunaan alat TDS meter sangat sederhana, dengan mencelupkan alat TDS meter pada sampel air, lalu dengan menekan tombol on/off maka nilai TDS akan muncul. Pada penentuan tingkat TDS, sensor lebih dipengaruhi oleh sifat hantar listrik pada cairan sampel dan apabila banyak kandungan partikel ion atau logam di dalam air [6].

Data yang akan dianalisis berupa pengukuran nilai kekeruhan air PDAM Tirta Keumuening Kota Langsa telah didapatkan data hasil pengamatan kerja praktek dengan mengukur nilai kekeruhan air menggunakan alat turbidimeter dan TDS meter.

Tabel 1 Data pengamatan rata-rata air baku (sungai dan waduk) PDAM Tirta Keumuening Kota Langsa

\begin{tabular}{c|cc|c|c}
\hline Tanggal 18-29 & \multicolumn{2}{|c|}{ Turbidity (NTU) } & \multicolumn{2}{c}{ TDS (Mg/L) } \\
\cline { 2 - 5 } januari 2021 & Sungai & Waduk & Sungai & Waduk \\
\hline Jumlah & 4227,2 & 2748,2 & 797 & 539 \\
Rata-rata & 422,72 & 274,82 & 79,7 & 53,9 \\
\hline
\end{tabular}

Tabel 2 Data pengamatan rata-rata air pada reservoir di PDAM Keumuening Kota Langsa

\begin{tabular}{c|c|c|c|c|c|c|c|c}
\hline Tanggal 18-29 & \multicolumn{4}{|c|}{ Turbidity (NTU) } & \multicolumn{4}{c}{ TDS (Mg/L) } \\
\cline { 2 - 10 } januari 2021 & IPA 1 & IPA 2 & IPA 3 & IPA 4 & IPA 1 & IPA 2 & IPA 3 & IPA 4 \\
\hline Jumlah & 212,56 & 262,27 & 260,52 & 165,24 & 764 & 779 & 785 & 879 \\
Rata-rata & 21,256 & 26,227 & 26,052 & 16,524 & 76,4 & 77,9 & 78,5 & 87,9 \\
\hline
\end{tabular}

\section{HASIL DAN PEMBAHASAN}

Pada Tabel 1 dan 2 dapat dilihat bahwa air yang sebelum dan sesudah pengolahan terjadinya perbedaan nilai kekeruhan. Sebelum dilakukannya pengukuran pada air pada reservoir, amati dan ukur terlebih dahulu air baku (sungai dan waduk) menggunakan turbidimeter dan TDS meter untuk mengetahui perbandingan air baku dan air pada reservoir. Penggunaan alat ukur turbidimeter itu sendiri bertujuan untuk melihat perbedaan nilai pada air baku dan pada unit reservoir. Begitu juga dengan penggunaan alat TDS meter yang bertujuan untuk melihat perbedaan jumlah partikel (padatan) yang terlarut didalam air baku dan air pada unit reservoir.

Pada Tabel 1 diperlihatkan hasil pengukuran dengan alat turbidimeter untuk air waduk dominan bernilai <100 NTU, sedangkan air sungai dominan bernilai >100 NTU dengan nilai tertinggi 1000 NTU ini disebabkan oleh faktor curah hujan yang mengakibatkan air sungai berdominan sangat keruh. Pada tabel diperlihatkan hasil pengukuran TDS meter dimana nilai paling tinggi pada tanggal 28 januari 2021 dengan nilai air waduk sebesar $152 \mathrm{Mg} / \mathrm{L}$ dan air sungai sebesar $118 \mathrm{Mg} / \mathrm{L}$. Untuk pengukuran temperatur air sungai dan waduk dominan akan bersuhu $20-30{ }^{\circ} \mathrm{C}$ begitu juga dengan air pada reservoar.

Pada Tabel 2 diperlihatkan bahwa setiap WTP/IPA menghasilkan nilai-nilai yang berbeda alasannya dikarenakan kapasitas penampungan setiap WTP/IPA berbeda-beda. Pada WTP/IPA I dan IV berkapasitas penampungan $40 \mathrm{~m}^{3} / \mathrm{L}$, WTP/IPA II dan III berkapasitas penampungan $60 \mathrm{~m}^{\mathrm{a}} / \mathrm{L}$. Pada pengukuran turbidimeter untuk air unit reservoir mendapatkan nilai tertinggi pada tanggal 28 januari 2021 dengan nilai WTP/IPA I (55,3), WTP/IPA II (68,7), WTP/IPA III (75,5), WTP/IPA IV $(25,1)$. Untuk nilai TDS meter di unit reservoir pada setiap WTP/IPA berkisar di atas $50 \mathrm{Mg} / \mathrm{L}$. Pada pengukuran temperatur di unit reservoir nilai suhu yang didapat diatas $20{ }^{\circ} \mathrm{C}$ terlihat pada tabel 3.2 dengan suhu tertinggi yaitu $28,4{ }^{\circ} \mathrm{C}$.

Untuk penggunaan beberapa kougulant ditambahkan pada saat proses pengolahan air PDAM Tirta Keumueneng kota langsa yang berperan sebagai penjernihan, oksidator, dan desinfektan. kougulant yang digunakan berupa tawas, MC-3, dan kaporit. Pada dasarnya kougulant yang sering digunakan oleh PDAM Tirta Keumueneng Kota Langsa adalah tawas. Untuk penggunaan MC-3 dan kaporit biasanya digunakan sesuai dengan keadaan air pada saat cuaca tertentu. Penggunaan/pemakaian kougulant sangat diperlukan dalam proses pengolahan, sebagai media penjernihan air. Alumunium sulfat $\left(\mathrm{Al}_{2}\left(\mathrm{SO}_{4}\right)_{3}\right)$ biasanya disebut sebagai tawas merupakan salah satu bahan kimia padat berupa serbuk kristal dengan warna putih keruh. Berfungsi untuk membantu proses pengendapan partikel-partikel kecil yang tidak dapat mengendap dengan sendirinya. Singkatnya fungsi tawas yaitu membentuk gumpalan dari partikel yang tersuspensi dalam air, sedangkan 
fungsi kaporit itu sendiri digunakan sebagai disinfektan atau media untuk mencegah timbulnya lumut mematikan mikroorganisme dalam air.

\section{KESIMPULAN}

Kesimpulan yang dapat diperoleh Dari hasil pengamatan yang dilakukan didapatkan pengukuran menggunakan turbidity meter dengan nilai tertinggi pada tanggal 28 januari 2021 dengan nilai air waduk sebesar $152 \mathrm{Mg} / \mathrm{L}$ dan air sungai sebesar $118 \mathrm{Mg} / \mathrm{L}$. Dan nilai tertinggi untuk air unit reservoir dengan nilai WTP/IPA I (55,3), WTP/IPA II (68,7), WTP/IPA III $(75,5)$, WTP/IPA IV $(25,1)$. Penggunaan alat turbidimeter dan TDS meter sangat membantu dalam pengukuran air untuk mengetahui nilai kekeruhan air yang akan disuplai kepada masyarakat. Turbidity meter yang merupakan alat pengujian kekeruan air dengan sifat optik akibat dispersi sinar, sebagai perbandingan cahaya pantulan dari cahaya yang datang dilihat dari tingkat kekeruhannya. TDS (Total Disolved Solids) merupakan alat untuk mengukur jumlah partikel (padatan) terlarut didalam air atau mengukur kepekatan larutan nutrisi hidroponik (konsentrasi larutan nutrisi) dengan satuan ppm (Part Per Million $=$ sepersejuta bagian) .

\section{DAFTAR PUSTAKA}

[1] E. Loniza and I. Syabani, "Portable Turbidimeter Dilengkapi Penyimpanan Data Berbasis Arduino," Med. Tek. J. Tek. Elektromedik Indones., vol. 1, no. 1, 2019, doi: 10.18196/mt.010103.

[2] A. Azis, "Watesqy ( Water Test Quality ) "Alat Ukur Kualitas Air Dengan Parameter Suhu , Bluetooth Dan Gsm ,” pp. 1-12, 2018.

[3] R. P. Wirman, I. Wardhana, and V. A. Isnaini, "Kajian Tingkat Akurasi Sensor pada Rancang Bangun Alat Ukur Total Dissolved Solids (TDS) dan Tingkat Kekeruhan Air," J. Fis., vol. 9, no. 1, pp. 37-46, 2019, doi: 10.15294/jf.v9i1.17056.

[4] N. I. Nuzula and Endarko, "Perancangan dan pembuatan alat ukur kekeruhan air berbasis mikrokotroler ATMega 8535," J. Sains dan Seni Pomits, vol. 2, no. 1, pp. 1-5, 2013.

[5] M. J. Parera, W. Supit, and J. F. Rumampuk, "Analisis Perbedaan Pada Uji Kualitas Air Sumur Di Kelurahan Madidir Ure Kota Bitung Berdasarkan Parameter Fisika," J. e-Biomedik, vol. 1, no. 1, pp. 466-472, 2013, doi: 10.35790/ebm.1.1.2013.4584.

[6] D. Manurung and E. M. Ginting, “Analisis Air Sumur Bor Desa Pekan Bandar Khalifah Kabupaten Serdang,” J. Einstein, vol. 1, no. 1, pp. 72-82, 2015, [Online]. Available: http://www.journals.cambridge.org/abstract_S0263034606000267\%0Ahttp://ejurnal.bppt.go.id/index.php/JAI/articl e/view/2452/2063\%0Ahttps://jurnalfarmasimalahayati.sch.id/index.php/jfm/article/download/7/3/. 